\title{
Clear Cell Sarcoma of the Kidney: A Case Report of an 11-year-old Boy and A Review of 11 Cases in Japan
}

\author{
Kazumi Taguchi ${ }^{1}$, Atsushi Okada ${ }^{2}$, Hiroyuki Kamiya $^{1}$, Yasuyuki Yamada ${ }^{1}$, \\ Keiichi Tozawa ${ }^{2}$ and Kenjiro Kohri ${ }^{2}$ \\ ${ }_{1}^{1}$ Department of Urology, Kainan Hospital Aichi Prefectural Welfare Federation of Agricultural Cooperatives, Yatomi, Japan \\ ${ }^{2}$ Department of Nephro-urology, Nagoya City University, Nagoya, Japan
}

\begin{abstract}
An 11-year-old boy experienced right flank pain on October 12, 2005. The pain was once alleviated but recurred on the following day, and the patient visited our hospital on October 13, 2005. An imaging study revealed a tumor, sized approximately $12.0 \times 7.5 \times$ $8.0 \mathrm{~cm}$, in the right kidney without metastases, for which right nephrectomy was performed. The tumor was solid, although degenerative necrosis and hemorrhage were partially observed inside the tumor. A histopathological study revealed poorlydefined, almost round tumor cells which were strongly stained with vimentin but not with cytokeratin or epithelial membrane antigen (EMA). Based on these findings, a diagnosis of clear cell sarcoma of the kidney in Stage II was made. A review of 10 previous cases reported in Japan during the past 10 years revealed that the affected patients were mostly aged 1 month to 4 years, while our case, occurring in an 11-year-old patient, was uncommon in respect to age.
\end{abstract}

Key words: clear cell sarcoma of the kidney, Wilms tumor, bone metastasis, National Wilms Tumor Study Group, National Wilms Tumor Study -5

(J Rural Med 2008; 3(1): 19-22)

\section{Introduction}

Clear cell sarcoma of the kidney (CCSK) is a rare malignant renal tumor mainly occurring in childhood, which was first described by Kidd et al. ${ }^{1}$ in 1970. The illness has been recently regarded as different from Wilms tumor, and has been classified as one of the unfavorable histology tumor, along with malignant rhabdoid tumor of the kidney (MRTK), and anaplastic tumor. As treatment methods have not been established for CCSK, the prognosis is extremely poor compared to that of Wilms tumor. We encountered a case of CCSK in an 11-year-old boy, and here present the

Correspondence to: Kazumi Taguchi

Department of Urology, Kainan Hospital, Minami-Honden 396,

Maegasu-Cho, Yatomi-City, Aichi 498-8502, Japan

E-mail: 464902@kainan.jaaikosei.or.jp case.

\section{Case Report}

An 11-year-old boy experienced right flank pain during a trip on October 12, 2005. He visited the emergency outpatient department of our hospital on the following day, and was hospitalized with a diagnosis of right renal tumor on October 13, 2005. The patient had a $10 \mathrm{~cm}$ elastic hard mass palpable in the right subcostal area.

Hematology tests showed hemoglobin $(\mathrm{Hb}) 9.8 \mathrm{~g} / \mathrm{dl}$, mean corpuscular volume (MCV) 70.9, and mean corpuscular hemoglobin $(\mathrm{MCH}) 23.7$, indicating microcytic hypochromic anemia. Urinary occult blood was positive with 20-29 RBCs/HPF in the sediment. As for tumor markers, immunosuppressive acidic protein (IAP) was high at 746 $\mu \mathrm{g} / \mathrm{mL}$, but no other abnormalities were observed.

A plain computed tomography (CT) of the abdomen revealed a large tumor in the right kidney with the pelvis compressed upward. On contrast-enhanced abdominal CT (Figure 1), the peripheral margin of the tumor was strongly enhanced, with sparse contrast effects inside the tumor, and sporadic degenerative necrosis was suspected. The upper portion of the tumor was seen to be supplied by the right renal artery and the lower portion of the tumor by the superior mesenteric artery; involvement of the lumbar artery was also observed. There was no remarkable swelling of the lymph nodes. On magnetic resonance imaging (MRI) (Figure 2), the tumor was shown as a low-intensity area by T1weighted image and an iso-intensity area by $\mathrm{T} 2$-weighted image. Also, there was subcapsular fluid accumulation, suggestive of hematoma. Based on these findings, a preoperative diagnosis of right renal cell carcinoma or Wilms tumor was made, and a transabdominal right nephrectomy was performed on October 21, 2005. A hematoma was observed under the hepatic capsule, but otherwise there were no particular abnormalities. The resected kidney measured $12 \times 9.5 \mathrm{~cm}$ in size and was $900 \mathrm{~g}$ in weight. A histopathological study of the resected tumor with optical 


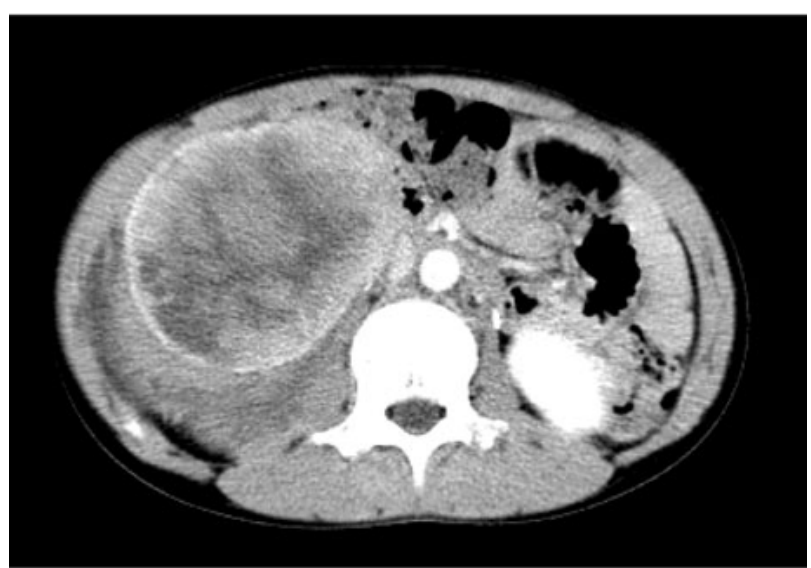

Figure 1 Enhanced computed tomography reveals the peripheral margin of the tumor strongly enhanced with sparse contrast effects inside the tumor and sporadic degenerative necrosis.

A

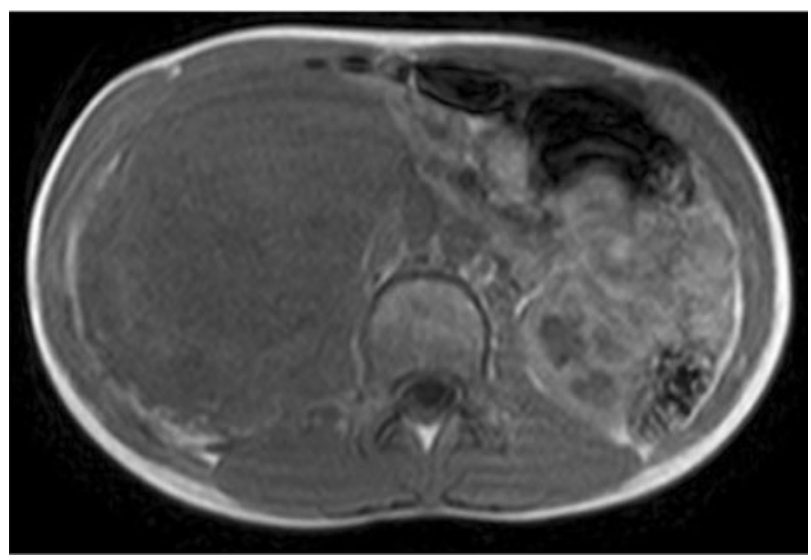

B

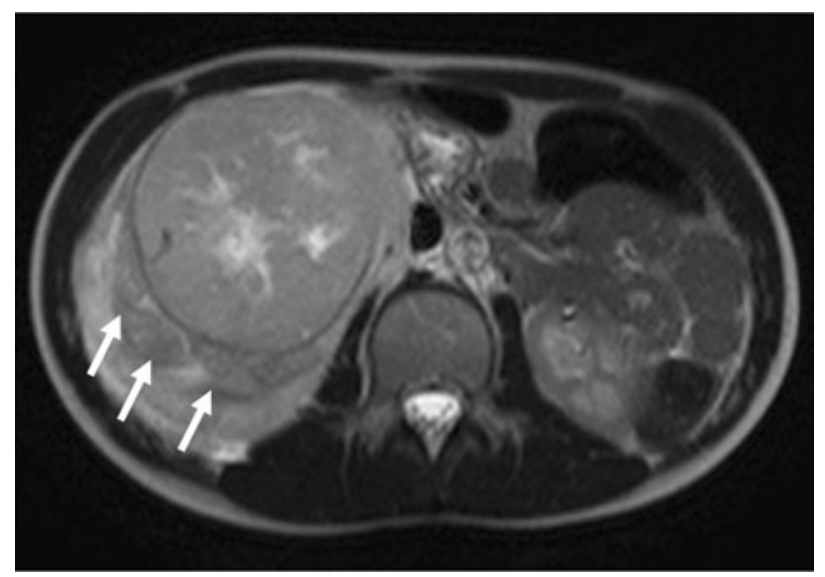

Figure 2 Magnetic resonance imaging shows the tumor as an isointensity area by $\mathrm{T} 2$-weighted image. There is subcapsular fluid accumulation, suggestive of hematoma.
A

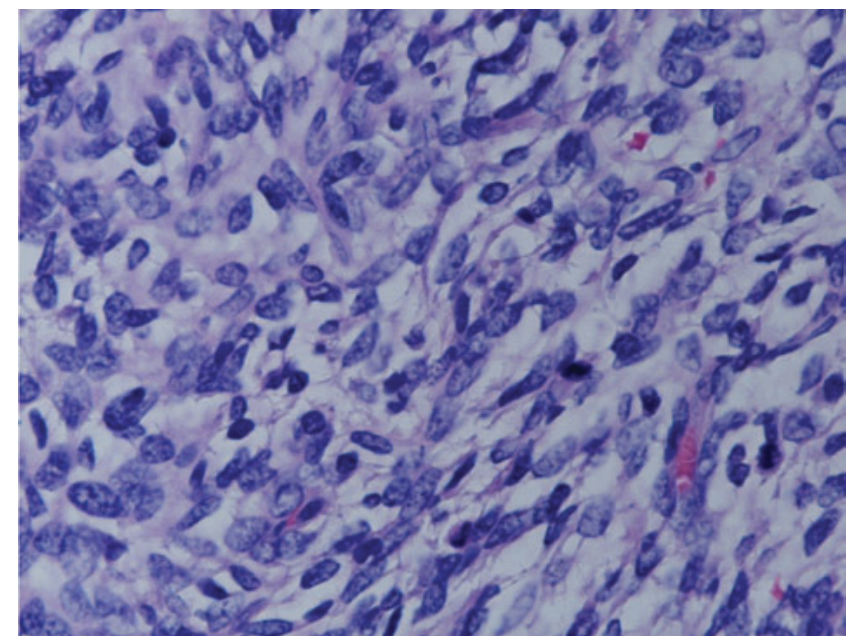

B

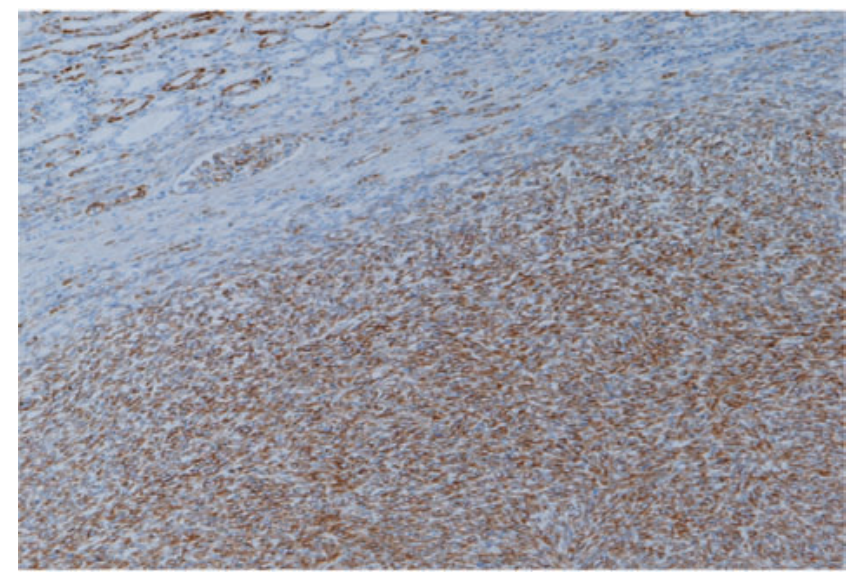

Figure 3 (A) The tumor cells are poorly-defined with poorlystained bright cytoplasm. The nuclei are consistent in size. The cells are almost round to spindle-shaped (HE stain, original magnification $\times 400$ ). (B) Strongly stained brown tumor cells are observed (vimentin staining, original magnification $\times 10$ ).

microscopy revealed poorly-defined, almost round tumor cells with poorly-stained, bright cytoplasm, and nuclei which were consistent in size (Figure 3A).

The tumor showed an invasive growth, and findings suggestive of venous invasion were partially observed. Immunohistological staining revealed that the tumor cells were positive for vimentin (Figure 3B), but negative for cytokeratin or EMA. Based on the above findings, a diagnosis of clear cell sarcoma of the kidney, Stage II, was made.

Although adjuvant therapy was considered when the definitive diagnosis was established, consent was not received from the patient's parents; thus, the patient was placed under observation. At present, 5 months after the surgery, the patient has had no signs of recurrence or metastasis. 
Table 1 Previous reports of the patients with clear cell sarcoma of the kidney (CCSK) in Japan

\begin{tabular}{|c|c|c|c|c|c|c|c|}
\hline Author & Year & Age & Sex & Size $(\mathrm{g} / \mathrm{cm})$ & Stage & Treatment & Remarks \\
\hline Miyazato & 1997.6 & $10 \mathrm{y}$ & M & $42 / 3 \times 2 \times 1$ & I & Chemo+Radio & Complicated by obstructive uropathy \\
\hline Watanabe & 1999.9 & $1 \mathrm{y} 11 \mathrm{~m}$ & M & $-/ 22 \times 16 \times 13$ & Unknown & Unknown & \\
\hline Ueki & 1999.10 & $2 \mathrm{y}$ & M & $3340 /-$ & I & - & Metastasis $(-)$ \\
\hline Mizuno & 1999.11 & $1 \mathrm{y} 8 \mathrm{~m}$ & M & $-1-$ & II & Chemo & Complicated by postoperative renal failure \\
\hline Matsumoto & 2000.11 & 0y1m & $\mathrm{F}$ & $-/ 9.5 \times 7.0$ & I & Chemo & $\begin{array}{l}\text { Postoperative complication of short-bowel } \\
\text { syndrome. }\end{array}$ \\
\hline Shinoda & 2000.12 & $3 \mathrm{y} 2 \mathrm{~m}$ & $\mathrm{~F}$ & $-1-$ & III & Chemo+Radio & Intra-abdominal dissemination $(+)$ \\
\hline Maeda Shinoda & 2001.7 & $2 y$ & M & $-/ 17 \times 8.5$ & II & Chemo+Radio & $\begin{array}{l}\text { Preoperative chemotherapy was given in } \\
\text { consideration of Wilms tumor }\end{array}$ \\
\hline Matsuda & 2002.8 & $4 y$ & $\mathrm{~F}$ & $-1-$ & III & Chemo+Radio & $\begin{array}{l}\text { Metastasis to posterior mediastinal lymph } \\
\operatorname{nodes}(+)\end{array}$ \\
\hline Kobayashi & 2005.5 & $1 \mathrm{y} 7 \mathrm{~m}$ & M & $321 /-$ & Unknown & Chemo & Preoperative chemotherapy $(+)$ \\
\hline Our case & 2005.12 & $11 \mathrm{y}$ & M & $900 /$ & II & - & Metastasis(-) \\
\hline
\end{tabular}

Chemo, chemotherapy; Radio, radiation therapy; F, female; M, male.

\section{Discussion}

CCSK is said to account for $1.6-4.1 \%$ of primary renal tumors in pediatric patients ${ }^{2,3)}$, or $3 \%$ according to a study by the national Wilms tumor study group (NWTSG). The disease is more likely to occur in males with a prevalence ratio between males and females of $6.7: 1^{2)}$, and the frequency of bone metastasis is known to be as high as $42-78 \%{ }^{4)}$. Metastases to other organs (lymph nodes, lungs, brain, and liver) can also occur ${ }^{5}$. Overall, distant metastases are found at presentation in about $4 \%$ of patients ${ }^{6}$. No familial or syndrome association exists. Some groups have used fineneedle aspiration cytology to assess patients who have diagnostic uncertainty before nephrectomy ${ }^{7-10}$.

El Kababri et al. ${ }^{11)}$ analyzed 13 cases of CCSK (among 277 cases of renal tumor) diagnosed between 1990 and 2002 at the Children's Hospital of Rabat. Based on their results, in children aged between 5 months and 9 years, the median age at diagnosis was 14 months, and the ratio between males and females was $5.5: 1.0$. The initial symptom was most commonly hematuria (in 4 cases), and there were no congenital diseases or family history of Wilms tumor in the patients. The tumors measured $7-26 \mathrm{~cm}$ in size and $450-3450 \mathrm{~g}$ in weight. The tumor stage was Stage I in $23 \%(\mathrm{n}=3)$, Stage II in $23 \%(\mathrm{n}=3)$, Stage III in $46 \%(\mathrm{n}=6)$, and Stage IV in $7.6 \%$ $(\mathrm{n}=1)$ of cases. Postoperative radiotherapy and chemotherapy were performed for 10 of 13 cases. During a mean follow-up period of 44 months, $31 \%(\mathrm{n}=4)$ of cases involved bone metastasis, $31 \%(n=4)$ involved $C R$, and $38 \%(n=5)$ involved fatal outcome.

Argani et al. ${ }^{6}$ investigated 351 cases, including cases in a trial by NWTSG with the protocol NWTS- 5 . The patients were aged 2 months to 14 years, the median age at diagnosis was 36 months, and the ratio between males and females was $2: 1$. The mean diameter of the tumors was $11.3 \mathrm{~cm}$. Nine different histological types (classic, myxoid, sclerosing, cellular, epithelioid, palisading, spindle, storiform, and anaplastic) were identified. Immunohistological staining was positive only for vimentin. In the anaplastic tumors, p53 gene expression was observed in two-thirds of the cases. The overall survival rate was $69 \%$.

As for the 11 cases reported in Japan (1997-2006) excluding our case ${ }^{12-21)}$, the mean age of the patients was 25 months (range: 1 month to 11 years) with a ratio between males and females of $7: 3$. The tumors measured $3-22 \mathrm{~cm}$ in size and $42-3,340 \mathrm{~g}$ in weight. The tumor stage was Stage I in 30\% ( $n=3)$ of cases, Stage II in $30 \%(n=3)$, Stage III in $20 \%(n=2)$, and unknown in $20 \%(n=2)$.

Postoperative radiotherapy and chemotherapy were performed for 4 cases (Table 1). The current NWTS-5 protocol recommends radiotherapy at 1080 Gy and multidrug chemotherapy (with AMD + VCR + DOX + CPM + etoposide) following surgery for all patients with CCSK in Stages I-IV. There has been a report describing that addition of DOX led to improvement in overall survival and relapse-free survival $^{22)}$. Factors associated with favorable prognosis include low-stage, younger age at the time of diagnosis, use of DOX therapy, and absence of tumor necrosis ${ }^{6}$. Among Stage I patients, the survival rate after treatment is said to be $98 \%$. Since $30 \%$ of patients experience recurrence at 3 years or more after diagnosis, and the percentage is unchanged even at 10 years, long-term follow-up is required ${ }^{23)}$.

In our patient, poor prognosis is likely indicated by the factor of the rather older age of 11 years, Stage II, and the presence of tumor necrosis. Continuing follow-up is required.

\section{References}

1. Kidd JM. Exclusion of certain renal neoplasms from the category of Wilms' tumor. Am J Pathol 1970; 59: 16a.

2. Marsden HB, Lennox EL, Lawler W, et al. Bone metastases in Childhood renal tumors: Br J Cancer 1980; 41: 875-879.

3. Beckwith JB. Wilm's tumor and other renal tumors of 
childhood: A selective review from the National Wilms' Tumor Study Pathology Center. Hum Pathol 1983; 14: 481492.

4. Wood DP Jr, Kay R, Norris D, et al. Renal sarcomas of childhood. Urology 1990; 36: 73-78.

5. Gonzalez-Crussi F, Baum EB. Renal sarcomas of childhood. A clinicopathologic and ultrastructural study. Cancer 1983; 51: 898-912.

6. Argani P, Perlman EJ, Breslow NE, et al. Clear cell sarcoma of the kidney: A review of 351 cases from the National Wilms Tumor Study Group Pathology Center. Am J Surg Pathol 2000; 24: 4-18.

7. Iyer VK, Agarwala S, Verma K, et al. Fine-needle aspiration cytology of clear-cell sarcoma of the kidney: study of eight cases. Diagn Cytopathol 2005; 33: 83-89.

8. Krishnamurthy S, Bharadwaj R. Fine needle aspiration cytology of clear-cell sarcoma of the kidney: a case report. Acta Cytol 1998; 42: 1444-1446.

9. Akhtar M, Ali MA, Burgess A, et al. Fine needle aspiration biopsy of clear-cell sarcoma of the kidney: light and electron microscopic features. Diagn Cytopathol 1988; 5: 181-187.

10. Drut R, Pomar M. Cytological characteristics of clear-cell sarcoma of the kidney (CCSK) in fine needle aspiration biopsy (FNAB): a report of 4 cases. Diagn Cytopathol 1991; 7: 611-614.

11. El Kababri, Khattab M, EL Khorassani M, et al. Clear cell sarcoma of the kidney. A study of 13 cases. Arch Pediatr 2004; 11: 794-799.

12. Miyazato M, Nakai H, Sasaki H, et al. Clear cell sarcoma of the kidney associated with the obstructive uropathy. A case report of ten-year-old boy. J Soc Pediatr Urol 1997; 5: 5056.
13. Watanabe Y, Shimizu M, Yamamoto $\mathrm{H}$, et al. A case report of Clear cell sarcoma of the kidney. Off J Jpn Assoc Pathol 1999; 16: 131.

14. Ueki S, Yamaguchi T, Kudo T, et al. A case report of Clear cell sarcoma of the kidney. Jpn J Pediatr Oncol 1999; 36: 324.

15. Mizuno D, Kato T, Hebiguchi T, et al. Clear cell sarcoma of the kidney associated with postoperative renal failure. A case report of a infant. Jpn J Pediatr Oncol 1999; 36: 537.

16. Matsumoto K, Kubota K, Nakayama A, et al. Clear cell sarcoma of the kidney associated with short bowel syn. A case report of a 1month-old girl. Jpn J Pediatr Oncol 2000; 37: 409.

17. Shinoda G, Yamaoka K, Hanioka K, et al. A case of clear cell sarcoma of the kidney with the early presentation of intraperitoneal metastasis. Jpn J Pediatr Oncol 2000; 37: 544-547.

18. Maeba $H$, Nishimura $Y$, Uemura $T$, et al. A case of clear cell sarcoma of the kidney using Central Pathology for diagnosis. Jpn J Pediatr Oncol 2001; 38: 461.

19. Ishizaki A, Hukuda A, Saito T, et al. A case of clear cell sarcoma of the kidney. J Jpn Pediatr Soc 2001; (105-7): 807.

20. Matsuda Y, Kusukawa N, Iwahori Y, et al. A case of clear cell sarcoma of the kidney. Acta Urol Jpn 2002; (48-8): 523.

21. Kobayashi Y, Inoue K, Nakamura T, et al. A case of clear cell sarcoma of the kidney with preoperative chemotherapy. Jpn J Pediatr Oncol 2005; 42: 146.

22. D'Angio GJ, Breslow N, Beckwith JB, et al. Treatment of Wilms' tumor: Results of the Third National Wilms' Tumor Study. Cancer 1989; 64: 349-360.

23. Walsh. Campbell's Urology. 8th ed. Saunders Harcourt, 2002; vol. 3: 2481-2493. 